\title{
RUY COELHO
}

L e L. - Gostaríamos que você comentasse um pouco a história da Faculdade de Filosofia, naturalmente dentro da Universidade, e fizesse uma comparação entre o que foi a "Faculdade dos professores franceses" (como nós a chamamos, embora não fossem só franceses), e o que ela é hoje.

R. C. - Bom, a Faculdade de Filosofia representava, de certa forma, a iniciativa de uma elite voltada para a Europa, mas com preocupação brasileira. Uma coisa que se diz e se repete constantemente é a seguinte: saber até que ponto a fundação da Faculdade de Filosofia, em São Paulo, foi uma atitude da elite, daquela elite que tinha perdido a Revolução e a hegemonia política.

L. e L. - A de 32?

R. C. - Sim, a de 32. E que tencionava marcar, no conjunto do Brasil, a posição de São Paulo como sendo mais avançada, mais civilizada. Seria a velha rivalidade entre São Paulo e Rio. São Paulo não era a capital, mas tinha uma tradição cultural. Foi uma aldeiazinha muito mais importante para o Romantismo brasileiro do que o Rio, que já era então uma cidade. Depois, na Semana de 22, São Paulo foi um centro intelectual. Tendo perdido a hegemonia política, São Paulo teria tentado então conquistar, ou preservar, o que os paulistas supunham ser a hegemonia intelectual. Há nisso tudo um fundo de verdade, mas há um exagero muito grande. Isso foi uma certa motivação, mas não foi o que suscitou os planos da Universidade. Esses planos vieram da reflexão sobre o ensino brasileiro, por uma geração que foi excepcional na História do Brasil. Eu não quero distinguir particularmente Fernando de Azevedo, se bem que ele, por sua personalidade mui-

Língua e Literatura, (10-13), 1981-84. 
to forte, tenha tido uma posição de liderança. Mas eu penso em toda aquela gente, sabe? Anísio Teixeira, Lourenço Filho, Roldão Lopes de Barros. As idéias sobre a renovação da educação. Uma geração excepcional em qualquer país do mundo, porque eram pessoas com nível de formação e de reflexão muito alto, e que não tinham posição política. Eram liberais, mas naquela posição liberal de 30 , que era bastante vaga. Não tinham um nível de pensamento filosófico como aquele que presidiu a certas reformas do ensino na Europa. Erá gente muito atenta ao Brasil. Mas aí eu vou procurar evitar chavões. essa história de "realidade brasileira" E impressionante que o $\mathrm{Dr}$ Fernando de Azevedo, por exemplo, na reforma da Escola Normal, se preocupasse muito em saber que elementos havia na escola existente e como poderiam ser aproveitados para a melhoria do ensino. Uma das coisas que ele me disse é que a Escola Normal da Praça da República, no entender dele, deveria ter uma atuação maior do que simplesmente dar uma proficiência técnica aos professores primários. Daí ele ter atraído os estudantes de sociologia, de psicologia. A idéia era abrir o secundário a interesses mais vastos. Assim, as Escolas Normais prepararam muito o ambiente para a fundação da Universidade de São Paulo. A princípio, a maioria dos alunos dos cursos de Filosofia, História, Sociologia, vieram daí. Os primeiros cursos, que eu não peguei, eram dados por professores franceses, e tinham a ouvi-los gente como Caio Prado Jr., Oswald de Andrade, Alcir Porchat.

L. e L. - Em que ano o sr. entrou?

R. C. - Eu entrei em 38. O aluno $n^{\circ} 1$ da Faculdade, o primeiro inscrito, foi o Cruz Costa. Na época, ele fazia a Faculdade de Medicina, porque era, afinal de contas, uma opção que lhe parecia menos má. Ele não se interessava por Medicina, mas no ambiente daquela época a pessoa fazia Direito, Politécnica ou Medicina. Então o interesse que ele tinha pelas ciências. então, havia gente com interesses variados. Algumas pessoas que se interessavam por História e Geografia vinham. A Universidade obedeceu então a um plano de implan. tação de ensino superior, com a idéia do cultivo da ciência pura. Mas tudo isso não surgiu como um puro movimento de reivindicaçāo, eu acho. Tem-se in. 
sistido muito nisso: "Ah, é a elite paulista que queria continuar numa posição hegemônica" Não digo que seja falso, mas não foi uma coisa que, no momento, respondesse tanto às circunstâncias de uma revolta militar pelo poder político.

L. e L. - Havia um desejo de saber, mesmo, de promover o saber.

R. C. - Sim. Havia um interesse muito grande, da parte de vários professores, que nas outras faculdadees tinham uma formação mais geral e um interesse maior por cultura. Porque hoje nós nos habituamos a considerar que o médico, por exemplo, é um profissional especializado, inteiramente desatento ao progresso da cultura. Mas naquela época.

L. e L. - Naquela época não era, não é?

R. C. - Exato, não era. Antonio de Almeida Prado escreveu livros, um deles se chamava Seara de Esculápio. O Prof. Luciano Gualberto escrevia poemas. Gofredo da Silva Teles tinha um livro de poemas que se chamava $A$ Fada Nua. Havia um culto à literatura, à poesia, e tudo mais. Vejam, por exemplo, Raul Briquet. Sua biblioteca, que foi incorporada à Biblioteca Central da Faculdade de Filosofia, por volta de 1938, tinha obras de Claparède. De 1936 até o fim da vida, ele fazia estudos de Psicologia. Escreveu um pequeno livro sobre o assunto, e era bem feito. Fazia conferências sobre a teoria de Einstein, sobre os confins dos corpúsculos, sobre situações intermediárias entre a matéria inanimada e a animada, o problema dos colóides e das células organizadas. Era um homem de grande cultura. Esse gênero de pessoas existia. E essas pessoas eram simpáticas à Universidade, foram os primeiros diretores da Faculdade. Mas, por outro lado, a Faculdade de Filosofia já começou ameaçada. Havia uma desconfiança total da parte das grandes escolas, uma hostilidade mesmo. Sentia-se que a Faculdade de Filosofia ia disputar uma certa situação privilegiada que era a dos professores das antigas Faculdades.

L. e L - Mas nessas Faculdades, como você disse, também havia pessoas interessadas numa Faculdade de Filosofia. $\mathrm{Na}$ Faculdade de Medicina, na Faculdade de Direito. 
Porque esse é mesmo o seu caso, não é? Faculdade de Direito.

R. C. - Eu entrei na Faculdade de Filosofia antes.

L. e L. - Antes? Ah, bom. Eu pensei que era clássico: primeiro Direito, depois Filosofia.

R. C. - Eu fiz Direito porque a família não concebia que se dizesse outra carreira. Quer dizer, eu fiz o vestibular de Direito e passei em 1? lugar. Depois de algum tempo, porém, eu deixei de ir lá.

L. e L. - Isso prova que aqueles professores da Faculdade de Medicina ou de Direito tinham razão de temer a Faculdade de Filosofia. Porque iam perder grandes cabeças!

R. C. - Veja, era uma certa incompreensão. Eu não preciso dizer que Medicina, Direito ou Engenharia são profissões importantíssimas. Mas certas pessoas que estavam nessas Faculdades não eram especificamente interessadas nessas profissões, apenas iam em busca de conhecimento geral. Era simplesmente a busca de algum curso universitário que expandisse os horizontes face à ciência . $\mathrm{E}$ aí então, com os professores franceses, abria-se essa possibilidade de cultivo de ciência pura. Cultivava-se a ciência em bases desinteressadas, quer dizer, não como formação profissional, mas como formação cultutural, marginal. Esse projeto foi entendido e teve o apoio do governo. Mais tarde, houve situações de crise. O Adhemar de Barros esteve disposto, e disse claramente em várias ocasiões, a liquidar ou transformar a Faculdade de Filosofia. Naquela época o Diretor não era eleito pela Congregação. O Adhemar tinha uma pessoa que era amigo pessoal dele, o Alfredo Ellis, um historiador já com uma obra toda publicada. E Adhemar - colocou como Diretor da Faculdade para liquidá-la. Foi nomeado como Diretor e tinha como primeiro encargo abrir aquilo a professores brasileiros. Porque os professores brasileiros são tão bons quanto os estrangeiros, etc. Mas, como Diretor, o Alfredo Eellis tomou contacto com os alunos e mudou radicalmente de posição.

L. e L - Isso foi em que ano?

R. C - Não sei dizer se foi em 39 ou 40 . Bom, enfim, o Alfredo Ellis, que devia liquidar a Faculdade, foi um dos ho- 
mens que a construíram. Todo mundo reconhece isso. Eu ainda me lembro dele recebendo o título de Professor Emérito, velho, falando com dificuldade. Ele disse: "Estou tão comovido que não posso falar, sou capaz de começar a chorar. Quando eu vejo o Lourival, o Ruy Coelho. "E nós todos de olhos úmidos, porque ele sustentou a Faculdade que o Governo queria acabar. E podiam ter facilmente acabado com ela! Aí, ele lutou, e convenceu as pessoas, e como amigo do Adhemar dobrou os propósitos dele, e permitiu à Faculdade de Filosofia se expandir Preparou essa expansão no pósguerra, quando havia mil dificuldades. Bateu-se contra a dispensa dos professores estrangeiros, bateu-se contra tudo o que ele tinha vindo fazer. De modo que ele foi muito importante. Naquele momento do pósguerra, a Faculdade estava com a primeira crise grave. Vários professores estrangeiros saíram, e saíram sem deixar uma base sólida. Outros, felizmente, chegaram: eram alemães, grande número de judeus. E outros professores franceses. Era um período de dificuldades, um período que foi o do término de nosso curso. Minha turma era numerosa, tinha 27 alunos. A anterior tinha só uns 3 ou 4 . Eram comuns aulas com 3 ou 4 alunos, nas primeiras turmas. Física, por exemplo, tinha 2: o Oscar Sala e outro que não lembro. OPacheco já tinha se formado antes. Então, a Faculdade daquela época era uma Faculdade de pequenos grupos, de convivências diferentes, alguns mais maduros, outros muito jovens. O Cruz Costa, por exemplo, já era mais maduro por reflexão, outros já tinham uma obra considerável. Eram pessoas atraídas pela possibilidade de realizarem cursos aprofundados de cultura geral. Depois veio o grupo dos normalistas. e aí vieram pessoas formadas nas boas escolas do país. O maior número de meus colegas de Ciências Sociais eram normalistas com bolsas. Esse primeira fase foi uma fase de contacto muito íntimo entre os alunos, e dos alunos com os professores. Os professores conheciam os alunos um por um. Havia os almoços na casa do Maugüé, e aí se discutiam projetos de vida e tudo o mais. Inclusive os namoros. $\mathrm{O}$ Maugüé namorou várias alunas. Sempre com amores infelizes, sempre disposto a casar Não pensem que era a coisa moderna de relação entre professor e aluno, que é outro capí- 
tulo: ele sempre pretendia casar-se. Então era uma comunidade muito unida. Um doutorado, por exemplo, era assistido por toda a comunidade. Eu assisti a defesa de teses como "O Cafesterol e alguns de seus derivados" da Jandira França; como se estava queimando muito café, faziam-se experiências químicas com ele. Assisti a outra tese cujo título nunca hei de esquecer: "Sobre a cloaca do Siphonops" Eu me lembro que o Marcus dizia: "Os senhores presentes podem fazer algumas perguntas adicionais. Mas nas cloacas do Michel (era o Michel Pedro Sawaya) ninguém põe o nariz!" Houve também um trabalho do Erasmo Garcia, sobre as guelras dos bagres das cavernas do Iporanga. Era muito importante, depois nós vimos. E houve uma tese sobre "A estrutura muscular dos piolhos de baleia"

L. e L - Isso parece piada! Era uma Faculdade surrealista?

R. C - Não, era um trabalho da maior importância: era o estudo da evolução. Nas cavernas do Iporanga - é o que eu guardei! - como era escuro, surgiram produtos de mutaçōes que, fora os bagres da caverna, eram liquidados na luta pela vida. Então havia os bagres cegos, com umas guelras muito especiais onde havia vestígios de uma respiração aeróbica. Entāo era a questão da evolução dos peixes. E os piolhos de baleia (que não são piolhos, são bichos grandões!) tinham perdido todos os órgãos, quase se reduziam ao aparelho digestivo. Isso é importantíssimo para a evolução. E a gente assistia a todas essas defesas de tese, a gente ia a tudo, a gente lia todos os livros: Todos é exagero, mas a gente lia de tudo. Houve uma doação do Governo Francês com várias coisas importantes, e aí abriu-se a possibilidade de uma biblioteca. Mas tínhamos um problema com o bibliotecário, o Raspantini. Ele tinha um ciúme imenso dos livros, para ele era um martírio deixar consultálos. Bom, mas então nós éramos um grupo pequeno. A princípio não tínhamos cursos, tínhamos um esquema mais europeu. O professor dava umas duas aulas por semana. Eu me lembro da sensação de frustração, de impaciência, que nós tínhamos, quando nos anunciavam que naquele dia o professor nāo ia dar aula. Para nós, era como se fôssemos ao cinema e a tela estivesse apagada. Não havia problema de frequência, cada aula 
era fruída intensamente. Era uma ânsia de saber coisas. E depois de formados, todos queriam dar aula. Havia brigas sérias para dar aula.

L. e L - E quando foi que essa faculdade inicial, dos alunos que se conheciam todos uns aos outros, terminou?

R. C - Terminou com o problema dos excedentes, os alunos que obtinham média de aprovação no vestibular e não tinham vaga. Vocês estão lembrados disso? Foi uma coisa violentíssima. O número de vagas foi ampliado, multiplicado por 5; de 20 passou a 100 . E acho que foi então que se criou o curso noturno, que devia ser dado por professores diferentes do diurno, mas acabou sendo dado pelos mesmos, por falta de gente. As mesmas pessoas davam diurno e noturno, recebendo o famoso complemento salarial pelo noturno. O que criou uma sentença judiciária interminável, porque a lei era dúbia. Eu acho que desde essa época, nós estamos lutando para alcançar uma outra estrutura. Acontece que a luta por essa nova estrutura deveria ter-se feito a partir de 68, que foi um ano muito importante. Desde 64 nós tínhamos ficado um tanto isolados, como um grupo de "subversivos" cercados, situados. Tinha surgido a guerrilha, a ligação de estudantes com operários, via-se o perigo dessa ligação. Em 68 , com o Costa e Silva, tivemos uma certa "primavera" uma aparente volta às liberdades, houve um movimento estudantil imenso, professores e alunos se reuniam para discutir as famosas paritárias. Quase não se deu aula. Mas, para mim, a experiência foi extremamente frutuosa. Havia idéias novas e experiências didáticas interessantes, seminários espontâneos. Daquilo tudo sairia alguma coisa de considerável. Aí veio a repressão maciça. Esses anos - 69, 70, 71 - foram os piores de minha vida. Vocês se lembram de que não se podia dar uma aula, houve semanas em que a polícia estava lá diariamente. A princípio, a gente resistia. Eles iam prender alunos e a gente não deixava.

L e L - Os alunos, durante as aulas, tinham medo. Preveniam a gente de que em classe havia pessoas estranhas ouvindo.

R. C. - A infiltração era maciça. Então a explosão de baixo e a pressão de cima ocasionaram uma ruptura muito 
grave de continuidade. Agravou-se isso com a expulsão da Maria Antonia e a nossa adaptação aos barracões, às salas emprestadas. Era a opressão, o autoritarismo total, o Conselho Universitário silencioso, as sessões da Congregação quase vazia. Eu me lembro de uma reunião da Congregação em que havia só 8 professores. Eu ia sempre. As pessoas não queriam ir à Congregação porque ela enfrentava a repressão. A Congregação sempre teve uma conduta exemplar, e disso eu tenho muito orgulho. Por exemplo: votou-se o encaminhamente de uma moção de protesto pela cassação e o processo de Mário Schemberg e do Cruz Costa. A Congregação aprovou por unanimidade, com os votos daqueles que, sabíamos, tinham um pensamento de direita: um Roque Spencer Maciel de Barros, um Laerte Ramos de Carvalho, votaram a favor, vamos dizer, a favor de um comunista conhecido, inscrito no Partido, como era Mário Schemberg. Mas muitos outros professores tinham medo de ir à Congregação. Então, daí por diante, foi a luta para refazer a Faculdade. Aí o Miguel Reale teve um papel importantíssimo. Em determinado momento, eu cheguei a ele e disse: "Magnífico Reitor, nós não temos condições de continuar com o curso de Ciências Sociais, nós estamos com um déficit muito grande de professores." Aí ele disse: "Vocês têm pessoas que possam substituir os que saíram?" Eu disse: "Nós temos alguns elementos um pouco verdes que a gente pode trabalhar" "Traga-me os nomes." Eu levo os nomes. Aí, em uma semana ele me chama e diz: "Olha, amanhã os nomes estarão no Diário Oficial." Aliás, há uma passagem que eu acho muito boa. Eu não estava presente mas me contaram. O Oswaldo Porchat, que é um homem muito sensível, como vocês sabem, foi ao Miguel Reale e disse, com os olhos úmidos: "Eu queria agradecer ao Senhor pelo que vem fazendo." De repente, ele parou e disse: "Bom, o Senhor não está pensando que eu estou aderindo ao Governo!. "Aí o Reale disse: "Não, Porchat, não. Mas o que é Governo e o que é oposição? Veja. Pode ter confiança em mim, que sou o mais liberal dos fascistas." Quer dizer, havia essa atmosfera. O Miguel Reale foi um sustentáculo da Filosofia. E ninguém punha em dúvida a posição do Diretor, o Eurípedes Simões de Paula. O Eurípedes tinha um almoço anual de 
confraternização com os oficiais da FEB. Ele dizia: "Eu nunca deixo de ir lá, porque lá eu digo: vocês estão enganados, aquilo não é comunismo. Eu sou comunista? Eu iria ficar à frente de uma coisa comunista? Vocês não me conhecem?" E com isso ele sustentou a Faculdade.

L. e L. - Uma Faculdade já bem diferente daquela da fundação...

R. C - As diferenças entre uma fase e outra foram muito grandes. No começo, a gente tinha vindo em busca de uma cultura geral, queríamos nos pôr a par do pensamento europeu. Mas aí aconteceu uma coisa curiosa com os professores europeus, que tinham suas próprias motivações. Essa gente vinha ao Brasil porque estava interessada no Brasil. E o que eles queriam era conhecer o Brasil. De modo que eles nos fizeram descobrir o Brasil. Eu me lembro do meu vestibular de Geografia, O Mombeig perguntou: "Pra que lado cresce São Paulo? De onde sopra o vento em São Paulo?" Eu respondi: "O Senhor sabe que eu nunca pensei nisso?" Ele disse: "Eu estou perdido. Os senhores não sabem Geografia?" Respondi: "Nós sabemos. "E ele: "Mas o Senhor não tem sensibilidade pra cidade onde mora? Quais são os eixos de atividades urbanas em São Paulo? O Senhor sabe que na Avenida Paulista, ainda em 1882, havia veados?" $\mathrm{E}$ alguém lá atrás disse baixinho: "E ainda há! " E o Mombeig continuou: "O Senhor sabe que o Parque Siqueira Campos é parte da floresta primitiva de São Paulo?" E assim ele nos interessava pelo Brasil desde o vestibular. E o Bastide nos levava à macumba. Ele já se interessava pelo Mário de Andrade, pelo Barroco, numa época em que nenhum europeu lidava com o Barroco. Ele dizia: "Isto é espantoso, e espantoso é um homem como Mário de Andrade que viu a importância disso aí!"' E ele nos fazia ler um ensaio do Mário de Andrade sobre aquele músico mulato, como é mesmo o nome?

\section{L. e L - O Padre Maurício.}

R C - E, o Padre Maurício. Então o Bastide, como todos os outros professores franceses, nos endereçava ao Brasil. O que houve depois é que os cursos adquiriram um aspecto muito mais profissional, menos geral. Naquele 
começo era mais o saber concreto, empírico, a pesquisa de campo, e não havia preocupação com a especialização. O Bastide fazia Sociologia da Literatura, da Arte, da Personalidade, da Cultura. Fez uma tese sobre Sociologia das Religióes. E cada um dos alunos ia-se endereçando a um desses rumos. Passamos a ser não mais uma Faculdade em que havia cursos gerais, como foi de início. E era natural. Na Europa, essa parte geral era dada no secundário, e as faculdades formavam egiptólogos ou especialistas em biologia marinha, não é? Agora nós temos grupos imensos de alunos, e temos a necessidade de especializar-nos, de concentrar-ios, de realizar pesquisas, transmitir técnicas, modos de proceder. Daí uma certa heterogeneidade dos cursos. Nossos problemas de crescimento foram muito graves, as mudanças se impuseram de uma maneira muito drástica, tivemos momentos de transição que eram rupturas grupais. A ruptura entre uma faculdade pequena, com alunos muito ligados aos professores, e uma faculdade com a ambição de absorver as massas. Não que se tenha uma faculdade de massa; apenas a própria elite pensante também se ampliou. Junto a isso, houve a ruptura do regime político brasileiro, a imposição de uma autoridade de cima para baixo, 20 anos de opressão. Eu estive fora durante 3 anos, depois de minha prisão e meu processo. Quando voltei, em 1977, eu tive uma impressão profundamente melancólica. Tinha-se chegado a um estado de marasmo. Quando eu assumi a Diretoria, vi que havia uma dificuldade das pessoas para imprimirem revistas, ou para dar certos cursos. Essas coisas foram melhorando aos poucos. Hoje, eu penso que há uma tentativa dos professores de retomar o diálogo com os alunos, e os alunos estão muito mais presentes hoje do que há dez anos. Há alunos que vèm reclamar de cursos, que querem mais cursos, cursos melhores!

L. e L. - Eles estão animadinhos!

R C - Não é? Hoje tenho cursos com alunos atentos (estou pegando meu exemplo não é pra me vangloriar, isto está acontecendo a vários professores), o que não acontecia em 77 Alguns dizem. "O que o senhor deu no princípio da aula de ontem? Me disseram isto ou aquilo, eu vou chegar mais cedo. "Não há mais aquela 
história de entram alguns e de repente saem outros. Antes, a sala de aula era um corredor, não era mais sala de aula. Agora há gente que fica, gente preocupada com o próprio curso, que faz sugestões aos professores, gente às vezes petulante, o que não me incomoda nada, acho até muito bom. Aliás, eu gosto de alunos que me chamam de você. Assim a gente se entende melhor Minha secretária antiga, Dona Maria Lúcia, comentava: "Que desrespeito pelo senhor!" Mas eu acho ótimo. Então, eu acho que agora nós estamos tentando nos reconstruir numa base mais ampla e com muitas dificuldades. E aí, haveria uma série de proposições pela frente. Eu penso que se nós tivéssemos tido um curso contínuo, sem rupturas tão violentas, estaríamos numa situação bem diferente. Vejam, não é só a questão da autoridade imposta de cima. Acho que o próprio crescimento gigantesco da Universidade levou a distorções e dificuldades: não ter onde alojar os alunos, etc. Eu penso também que a Maria Antonia está-se convertendo num mito. Todo mundo fala na Maria Antonia, mas vejam, não podemos ficar sonhando com o paraíso! Aquilo eram outras circunstâncias, um número muito menor de alunos. Aquela intimidade que havia, aquele ambiente de discussão de problemas em todos os botecos, em todos as lanchonetes do bairro.

L. e L. - Mais fora de aula do que em aula.

R. C. - Exato.

L. e L. - Consta que o Cruz Costa teria dito que, na Maria Antonia, se aprendia mais nos corredores do que nas salas de aula.

R. C. - Bom, a gente decidia muitas vezes as coisas no saguão. Eu saía conversando com o Candido e íamos tomar um café. Ele não toma café, mas acompanhava a gente. Descíamos, e encontrávamos o Sérgio Buarque de Hollanda. "Sérgio, onde você vai?". "Eu vou à Pioneira." "Vem tomar um café conosco. Ô Sérgio, você conhece um tal de Fernando Novais? É bom?" "Ah, esse é um rapaz excelente!" "Estão falando dele pro curso de Ciências Sociais. " "É ótimo, tenta, você vai ver. "Tá bom, então eu vou falar com ele." Não havia os problemas administrativos. As coisas se decidiam as- 
sim, do modo mais fácil possível. Agora as coisas estão muito mais institucionalizadas. Mas, quanto à Maria Antonia em si, não era bem o que se diz. Tivemos problemas muito graves lá, era um pardieiro horrível, com deficiências de instalação muito grave, muitas dificuldades de funcionamento. O que houve foi uma espécie de união sagrada pela Maria Antonia, depois de 68. Hoje nós temos o problema da formação básica dos estudantes. Eu não quero voltar aos tempos da Maria Antonia, mas penso naquilo que ela dava, uma base mais geral. Penso no primeiro e no segundo ano, esses cursos introdutórios não sei como vocês fazem em Letras.

L. e L. - É, mas com tal deficiência no secundário, será que um ou dois anos resolvem?

R. C. - Por isso mesmo! Há três anos estou dando aulas no primeiro ano. A Marilena e o Gianotti também, resolveram dar alguma coisa mais geral no início do curso.

L. e L. - Nós também temos dado aulas no primeiro ano. Sem que a gente houvesse conversado, de repente vimos que muitos estavam voltando ao primeiro ano, vendo que o problema era ali. Voltar ao primeiro ano não era uma decisão isolada, era de muita gente, pedindo para dar aula no primeiro ano. - Mas como estamos no fim da gravação, talvez você quisesse fechar com alguma coisa que desejasse dizer, talvez nessa linha do rumo futuro.

R. C. - Certo. A questão é a seguinte. A Faculdade de Filosofia era, evidentemente, um projeto de elite, ligada a uma série de interesses. Era uma elite que queria ampliar e engrandecer o pensamento brasileiro, entenda-se, o pensamento dominante, que queria difundir seus próprios ideais e valores. E eu não sei bem que outros valores poderiam ser difundidos. A idéia de uma Universidade para as massas me parece inviável, eu acho porém que isso deveria ser pensado. Eu não vi, em tudo o que aconteceu, uma direção, algo que apontasse para esse rumo da Universidade de massa. Estamos com o problema de saber o que vale na Universidade. Consideramos a Faculdade de Filosofia como tendo um cunho universitário de maior peso, pelo fato de nós cultivarmos a ciência. Agora. como fazer isso, como 